12. Jessop.- "The Physiology of the Intra-Ocular Muscles,"Bericht Ueber die Internat. Ophthal. Congress, 1888.

13. BarRetT.- Transactions Intercol. Med. Congress of Aust., Melbourne, p. $588,1889$.

14. Morat et Doyon.-Arch. de Physiol., p. 507, 1861.

15. LANGLEY and ANDERSON.- " The action of Nicotine on the Ciliary Ganglion and on the endings of the Third Cranial Nerve." Jl. of Physiol., Vol. XIII, p. $461,1892$.

16. "On the Mechanism of the Movements of the Iris." Jl. of Physiol., Vol. XIII, p. $55 t, 1892$.

17. Ricket. Dictionnaire de Physiologie. 1895.

18. Tscherning.-Optiq. Physiol., 1898.

19. Barrett, J. W.- "Do Mammals Accommodate?" Ophthal. Rev.. Sept., 1898.

20. BeER, Theodore.-Wien. Klin. Wochenschr. and Ophthal. Rev., Sept., 1898.

21. Collins, E. Treacher.-Bowman Lecture, 1920. Trans. Ophthal. Soc., Vol. XLI. 1921.

22. Henderson, Thomson.-Doyne Memorial Lecture. Trans. Ophthal. Soc., Vol. XLVI, 1926.

23. WoOD, Jones F.- "The changing point of view." Bancroft Memorial Lecture. Med. Jl. of Australia, August 24, 1931.

24. Barrett, J. W.-Med. Jl. of Australia, Feb. 6 and May 21, 1932.

25. Osborne, W. A.- "A Problem in Biology." Med. Il. of Australia, Sept. $19,1932$.

26. Mayou, M. S.-Brit. Jl. of Ophthal., 1932 and 1933, and correspondence with J. W. BARRETT.

27. Fincham, EdGAR F.-" The Mechanism of Accommodation."

\title{
A MELANOMA OF THE IRIS WITH PATHOLOGICAL FINDINGS*
}

\author{
BY \\ FRED T. TOOKE \\ FROM THE DEPARTMENT OF OPHTHALMOLOGY, \\ ROYAL VICTORIA HOSPITAL, MONTREAL, QUEBEC
}

Melanomata of the iris are not of infrequent occurrence and have been recorded and exhaustively described by Fuchs, Treacher Collins, Gilbert, and Verhoeff, to mention only a few outstanding authorities. They occur, according to Fuchs, under two different forms. The first consists in a blackish tumour which apparently goes out from the stroma of the iris into the anterior chamber and arises from the proliferation of the chromatophores. The second type of melanoma has its seat at the pupillary margin of the iris and develops from the cells of the retinal pigment layer at the spot where it is reflected upon the anterior surface at the pupillary margin. Sometimes in consequence of the pupillary reaction these nodules become separated and detached and lie free in the anterior chamber. This type is not infrequently seen in the horse as has been described by Treacher Collins.

\footnotetext{
* Read before the American Ophthalmological Society, Hot Springs, Virginia,
} June 3, 1937. 
The recognition of a pure melanoma and one as differentiated from a similar type of tumour with an underlying or complicating sarcomatous origin is frequently beset with difficulty. One is to be distinguished from the other only by determining from the previous history or from close observation, or preferably from both, whether a process of extension is in progress or not.

An instance of a pigmented neoplasm of the right eye, presumably originating from the iris stroma was brought to my attention a little over two years ago (January, 1936). From the history of its occurrence and development, if not by its actual clinical manifestations, no little concern was felt by myself as well as by the members of my staff on seeing it for the first time.

Dr. G. T., aged 24 years, consulted me on the recommendation of Dr. Evatt Mathers and Dr. Albert Doull, of Halifax, N.S., who had kept the patient under close observation for a number of years. The subject was a rather delicate looking young man, possibly due to the fact that he was just completing his final year as a student in medicine, and also because he had suffered from an attack of quinsy, for the relief of which his tonsils had been enucleated. The patient was not of the brunette type, though not a blonde, and the stroma of the irides appeared as a light grey colour. His general health had been good and there had been no tumours or instances of tuberculosis reported in his family. His physical examination was negative and no moles were present elsewhere on the body. The patient stated that a tiny pin-head pigmented spot appeared on the right iris at a point representing 10 o'clock, seven years ago. It was midway between the filtration angle and the pupillary margin. Three years ago it embraced the central half of the iris stroma, an upper and a lower segment remaining free from pigment encroachment. It was one and a half times as long as it was wide. One and a half years ago it had extended further upwards to the root of the iris, and downwards to the pupillary margin. A heaping up of the iris pigment was first apparent to his former consultants in August, 1935. The growth, apparently increasing during this space of time, became arrested and it had not extended from there until he reported to me for an opinion. The patient had never complained of pain and vision had not been impaired.

I will condense my remarks by stating that all the ocular tissues other than the iris were normal. The anterior chamber was of normal depth, the pupil was free from adhesions and active to light and accommodation. The stroma of the iris was generally of a bright grey colour. On focal examination the involved portion of the iris extended from a point just beyond 9 o'clock at the pupillary margin below to within $2 \mathrm{~mm}$. of the corneo-scleral margin above, and upwards from a point representing 11.30 
o'clock below at the pupillary margin up to the limitations of the root of the iris above. The area was thickened or raised, but only to a moderate degree, and not sufficiently to diminish appreciably the depth of the anterior chamber. The process of melanosis did not particularly involve the endothelial layer of the iris, and the tracery or crypts of its surface seemed to be very

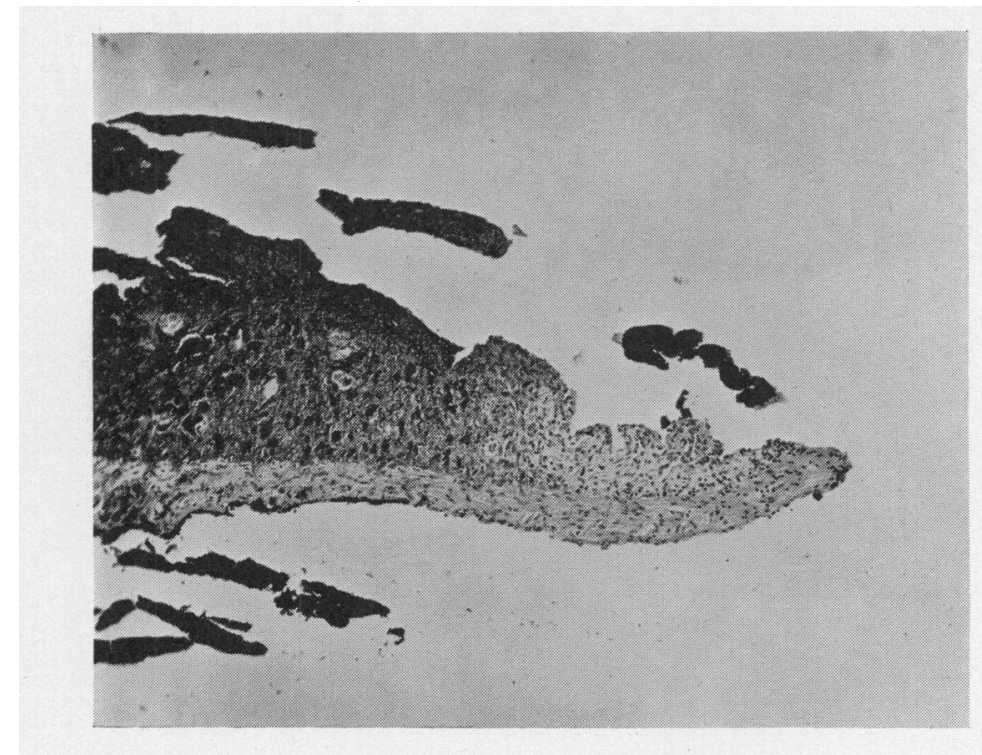

FIG. 1

Radial section through iris low power, haematoxylin-eosin. Retinal pigment layer largely detached. Migration of pigment epithelium through supporting unstriped muscle cells. Pigmented portion of stroma consists of small amorphous pigment cells (chromatophores) and some definitely larger and more deeply staining cells (mesoblastic melanoblasts). Pigmented portion of stroma ceases as one approaches the pupillary margin.

little, if at all, disturbed. The slit-lamp verified these observations and also supported the opinion that the process of melanosis was sharply confined to this area, there being no pigmented extensions at either edge. There was, however, a definite ectropion of iris pigment, these cells presumably extending from the retinal pigment layer at the pupillary margin. This was a chocolate colour, while the pigmented iris above resembled more the colour of ground coffee grains. The slit-lamp did not show any excursion of pigment cells on the corneal endothelial layer in front or upon the lens capsule behind, and there were no leucocytes in the anterior chamber. There was no undue element 
of vascularity on the surface of the tumour itself or near the pigmented excrescence at the pupillary margin. The pupil dilated with ease with homatropine, showing no evidence of synechiae. The fundus oculi showed no evidence of a naevus of the choroid; tension with the Schiötz's tonometer was normal;

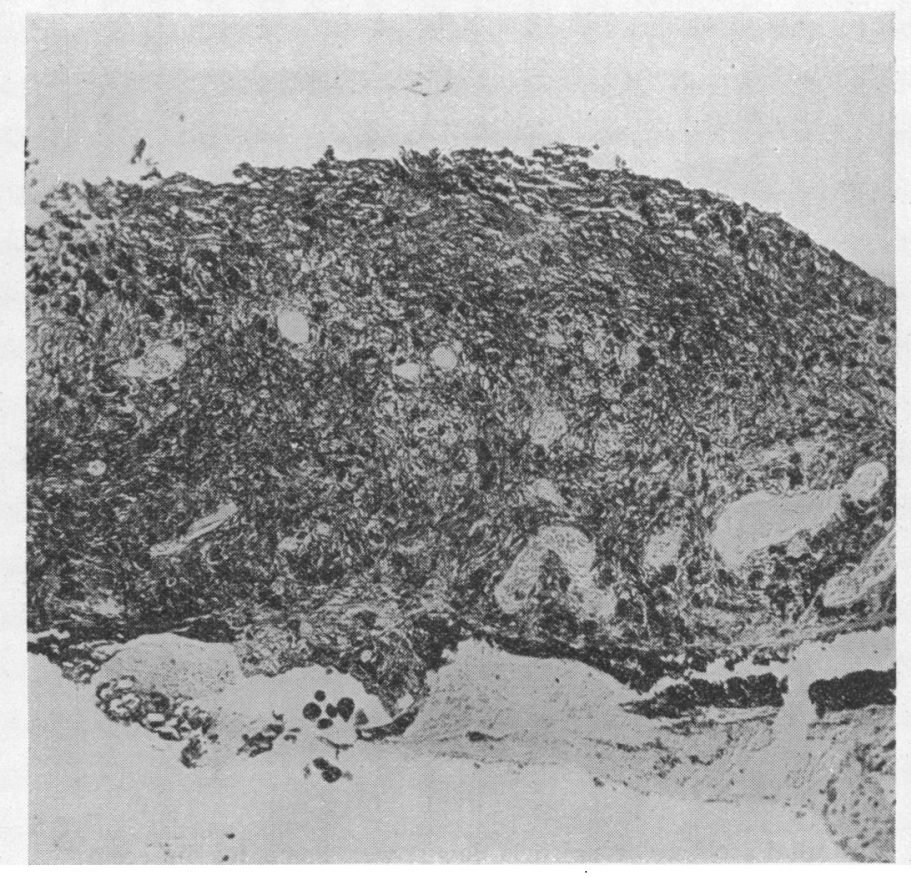

FIG. 2.

Radial section through iris, high power, haematoxylineosin. Iris increased at least three times its normal thickness. Little if any trace of the various component layers of iris due to the homogeneous mass of chromatophores and melanoblasts. Some apparent migration of pigment epithelium.

transillumination was negative, and vision with correction was unimpaired.

The possibly serious character presenting itself was explained to the patient, an ultimate diagnosis being reserved for a biopsy. As he was taking his final examinations a delay of four months was granted after reviewing the progress of the tumour's behaviour. On his return to Montreal, the picture was precisely the same as when he was first seen; there were no pigmentary extensions from either edge of the growth, the tumour had not increased in size, it was not engorged with blood vessels, the 
pupil was active, tension was not raised, and vision with correction remained normal.

A crescentic conjunctival flap was made above to the limits of the lateral edges of the growth. An exact definition was assisted by two spots of aniline gentian violet to define the extent of the proposed corneal section. An unusually small Graefe knife was inserted just below one spot and a counter puncture made just

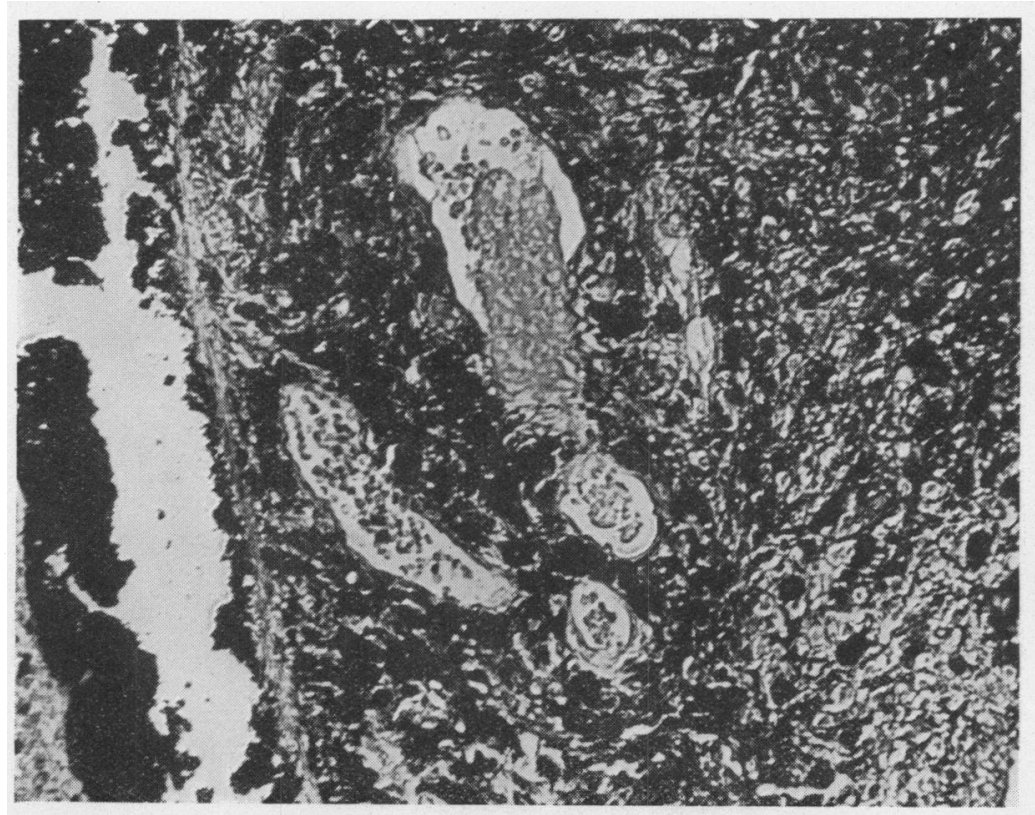

FIG. 3.

Radial section through iris, high power, haematoxylin-eosin. Separated pigment epithelium. Migration of pigment epithelium through unstriped muscle cells of stroma. Marked heaping up of mesoblastic melanoblasts about the walls of the dilated capillaries.

beyond the second. The incision was perilously close to the ciliary body coming out underneath the conjunctival flap. Fortunately the iris did not engage with the knife and there was no hyphaema or escape of vitreous. Tyrrell's blunt iris hook was inserted at 9 o'clock and the iris drawn out from the incision and sectioned horizontally up to its root. It was then drawn across the incision to its farthest limits and torn away from the iris root, the iris again being cut vertically in such a manner as to include completely the pigmented area in the excised portion of iris. Sutures which had been inserted as a precautionary measure were drawn up. The pillars were replaced and recovery was 
uneventful. I saw the patient six months after his operation with a perfectly functioning eye. There was no further extension of pigment into the iris stroma; the upper edge of the lens, and indeed the fibres of the suspensory ligament, could be clearly seen through the coloboma with the ophthalmoscope and there did not appear to be the slightest involvement of the anterior ciliary processes. The tissue was hardened in formalin and sections cut in paraffin. These were stained in haematoxylin

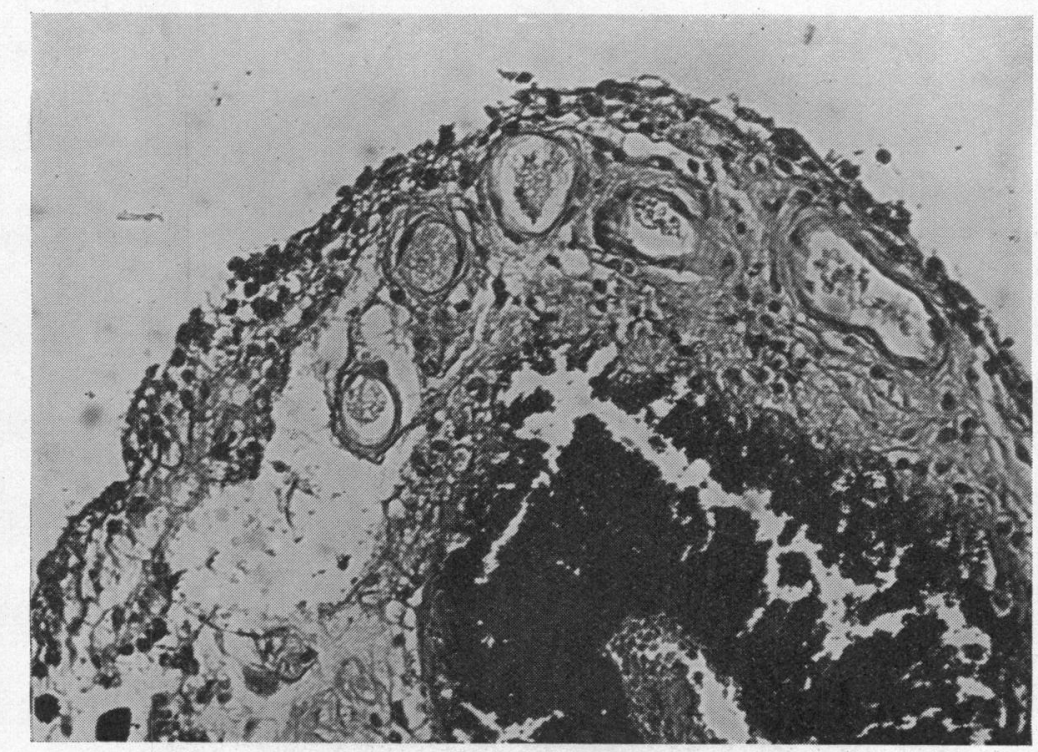

FIG. 4.

Section through pupillary margin reflecting on itself. Relatively few, if any, pigment cells within the stroma proper. Terminal capillaries of circulus iridis minor show few, if any, pigment cells about the capillary walls. No perivasculitis. Haematoxylin-eosin.

and eosin and with the same stains after bleaching. Sections were also stained with Mallory's phosphotungstic acid haematoxylin as well as by van Gieson's method.

A view of the iris on section reveals a strip of tissue apparently three times as thick as one normally finds it except at that portion where one would anticipate the presence of the sphincter iridis, namely, near the pupillary margin. On examining a section microscopically, one stained with haematoxylin and eosin, a certain definite loss of relationship has been inevitable due to a partial separation of the retinal epithelial layer in the preparation of paraffin sections. Some of these pigmented 
epithelial cells are adherent and in sufficient quantity to maintain our argument. The supporting layer of unstriped muscle cells anterior to the pigment or epithelial layer, can in places be outlined with a definite element of clarity and it is in this layer of cells that a very clear picture presents itself substantiating an

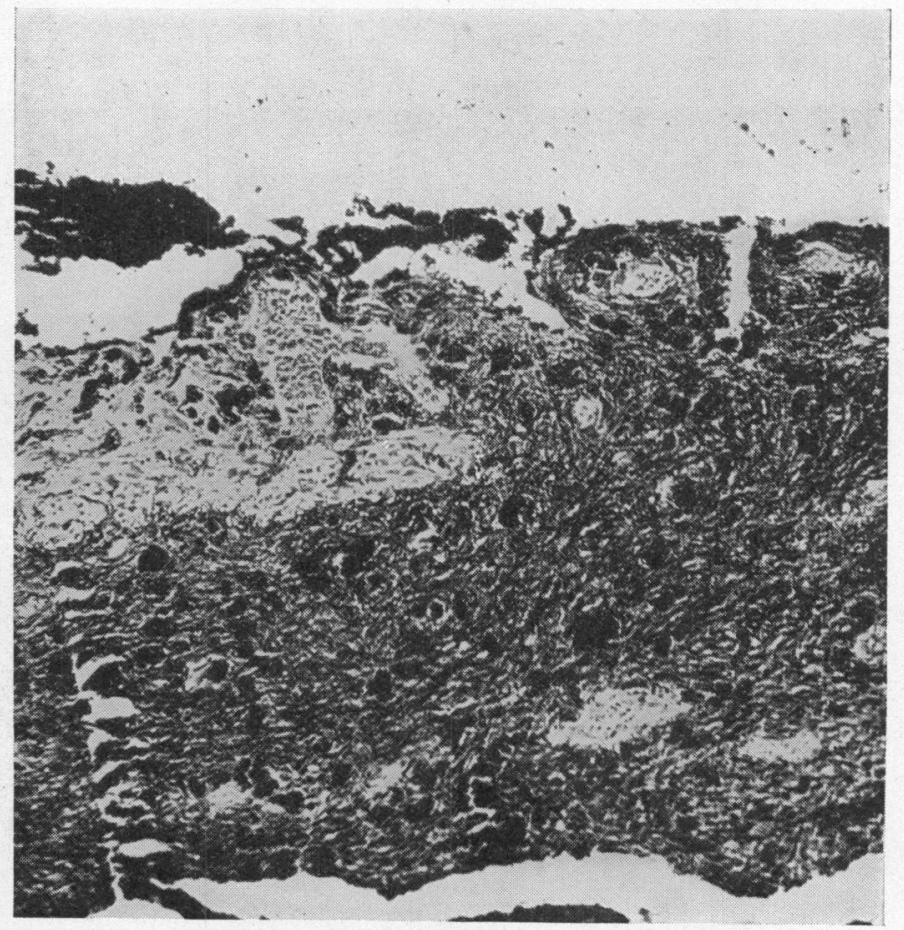

FIG. 5 .

Radial section through iris, haematoxylin-eosin. Definite migration of ectodermal melanoblasts (retinal pigment epithelium) through supporting unstriped muscle tissue of stroma. These cells find their way later into the deeper layers of the iris. Many coarse pigment cells about a large capillary of the muscular layer.

idea at least regarding the genesis of the pigment cells as noted in a hyperplasia such as the case under discussion. Where unstriped muscle is present, and where the pigment layer is at least partly adjacent, one can note quite clearly a migration of these cells apparently not arrested by the muscle fibres. These pigment cells extend definitely through it and apparently into the more or less amorphous zone of the stroma proper. 
A feature to be noticed during the course of migration is the affinity these cells have for the fine capillaries as one sees them in the muscular layer. The cells are, for the most part, black or chocolate colour affording little if any cell definition or distinction. Those passing through the muscle tissue are possibly sometimes smaller, possibly more definitely granular with a slightly less intense degree of pigmentation. Some of the smaller cells almost appear to have a direct relationship with the lining cells of the

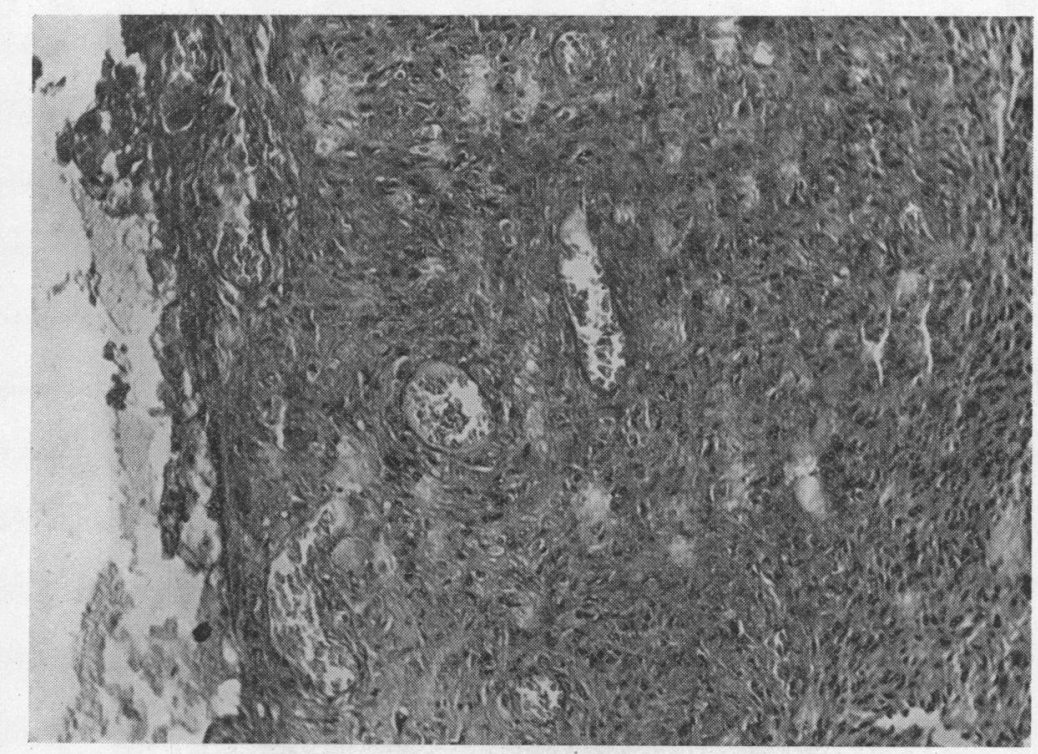

Fig. 6.

Bleached section of iris, high power, haematoxylir-eosin. Migration of pigment cells through the muscle fibres. Have largely the same characteristics of pigment epithelium, cuboid, with large nuclei. Many such cells are scattered through the stroma and others noted about the vessel walls. No signs of perivasculitis. Stroma cells proper are largely spindle cells with deeply staining nuclei. Do not branch or bud.

capillaries, while, of course, the larger ones are somewhat extrinsic or more remote. The walls of the capillaries are usually remarkably thin. Proceeding forward into the stroma proper one sees a meshwork of more or less amorphous reticular tissue supporting a conglomerate mass of cells definitely granular in character and of a light coffee ground colour as contrasted or compared with the cells of the retinal pigment layer. Interspersed within this stroma of lightly pigmented cells are scattered about larger and definitely more deeply stained cells comparable 
in some respects to those of the pigment epithelium which I have already referred to as migratory cells. There seems to be a definite affinity for these larger, more deeply staining cells for the capillary walls on the part of these apparently gross feeders than is noted in that part of the iris where a hyperplasia of retinal cells is not so evident. Naturally, all definition of the endothelial cells covering the stroma is completely obscured. In bleached sections the cells of the retinal layer of the iris, or those of ectodermal origin, appear as large and epithelial in character differing from the spindle or fusiform shape of the mesodermal or melanoblastic elements of the stroma proper.

The question to me has been not so much the clinical history of the case and its subsequent behaviour following operative interference, but rather the genesis of the hyperplasia of pigment producing cells, their origin, character and the rôle they play in the formation of what some regard as a simple hyperplasia of pigment cells or others as a true tumour. The argument regarding the derivation of the cells responsible for pigmented growths has been waged by authorities of undoubted reputation, but apparently the end is not yet. The opinions advanced up to date regarding their origin are as follows :

1. They arise from the epithelium or are epiblastic in origin. (Unna, Kromeyer, Marchand, Gilchrist.)

2. They are mesoblastic in origin and are:

a. Young connective tissue cells. (Simon, Kirchow, Riecke.)

$b$. They arise from proliferation of the lymphatics. (von Recklinghausen, Lubarsch, Herxheimer.)

c. Their origin is from the endothelium and perithelium of blood vessels. (Pick, and Jodasshon.)

$d$. They originate in the sheaths of the nerve fibres. (Soldau.)

3. They are specially characterised cells of mesodermal origin. (Ribbert.)

I wish to acknowledge at the outset of my discussion the constructive assistance I have had through the co-operation and interest shown in this contribution by Dr. Theodore Waugh of the Department of Pathology, as well as that of my colleague Dr. John V. V. Nicholls, whose opinions I am happy to incorporate with my own.

The development of the iris is partly from epiderm and partly from mesoderm; each part has its own particular system of pigment cells. Those in the anterior portion of the iris, or the 
mesodermal portion, are analogous to the pigmented cells of the choroid; they are generally termed " chromatophores." They, however, are more precisely termed " mesodermal melanoblasts", and correspond to the cells met with in Mongolian spots of the skin. They are " dopa " positive, at least in embryonic life and apparently may vary in their " dopa " reaction, manifesting in this way a dual function. Theories regarding the origin of these so-called mesoblastic melanoblasts are numerous. Regarding the character of this type of cell, it has been pointed out that in embryonic life they can be seen growing in from the posterior surface of the iris.

In respect to these stroma cells it would seem that light may have some effect in stimulating their activity, and it is the stimulation of such an activity, which changes the blue eyes of new-born to darker colours later in life. In their neighbourhood in the iris are histiocytes, highly phagocytic cells, which correspond to the chromatophores of the skin. These are not melanin producing cells and never "dopa" positive; they are merely reticulo-endothelial elements, branching, highly phagocytic, and store large quantities of pigment and hence are more intensely black. Whether the mesodermal melanoblasts are true mesoderm or displaced ectoderm is a debatable point; our sections at least are more suggestive regarding one point of view. Some authorities hold that these cells are simply those which have phagocytosed pigment from epithelial pigment formers; that is, that they are merely chromatophores. "The "dopa " reaction would seem to rule out this possibility.

It is within the realm of physiology to have these mesodermal melanoblasts of the anterior portion of the iris, or stroma, become active pigment formers after birth, giving colour to the otherwise blue iris. It is the variations in the location and amount and character of this activity which give the marked differences in eye colour. If it is particularly emphasised in one area, definite localised dark granular spots appear in the iris. If a greater but localised or isolated area appears it is termed a "naevus or melanoma." Neither of these terms can be regarded as strictly speaking correct as used elsewhere in a pathological sense, for the cells under discussion possess no naevus cells analagous to naevi of the skin and while as a growth they might be considered tumours they are probably not neoplastic.

They may actually represent focal areas of hyperplastic activity of the mesodermal melanoblasts. I venture to suggest as a modified alternative that melanoblasts of ectodermal origin, after migration into the stroma, which represents the mesoderm, may take on altered characteristics, possibly due to their intimate association with the capillary walls. If a mass of these cells 
represent an area or focus of unusual dimension probably the term melanoma is in a sense justifiable. If the reaction is more diffuse and extensive one would prefer the term "melanosis." This activity does not appear to lead to sarcoma production, though the possibility cannot be denied on pathological grounds. Such growths rarely occur from the Mongolian spots in the skin.

In contrast to the mesodermal melanoblasts we have the " ectodermal melanoblasts" which occur on the back of the iris which are an extension of the retinal epithelium and are ectodermal in origin, they are analogous to the pigment of the epidermis of the skin. Their relation to nerves as brought out by Masson is an interesting question but beyond the subject here.

It has been generally supposed that this layer of cells is much more stationary in character than the pigment cells of the stroma and is not prone to areas of hyperplasia. As I have already shown in my sections there is some definite indication, however, that cells displaced from it make their way forward where they may possibly lie in clusters known as " klumpenzellen." Their pigment is often of rod-like character and in this respect is similar to that of the posterior retinal pigment and different from the anterior uveal type. It seems quite possible, however, that they may be merely histiocytes which have phagocytosed pigment from the retinal layer-namely, true chromatophores.

Tumours of this retinal layer, as in the epidermal derivations of the skin, take the form of pigmented papillomata or warts. They frequently occur in the horse and may protrude into the pupil as Treacher Collins has shown. Some authors refer to them as melanomata or as papillary epitheliomata of the inner layer of the iris. Their cells are large and epithelial in character differing from the spindle or fusiform shape of the mesodermal melanoblastic elements. The growths are true tumours with supporting blood vessels and stroma. They lie as a rule near the pupillary border. Occasional cystic forms have been described (Gilbert). Metastasising immature growths have also been reported (Hirschberg and Birnbacher). Such, however, are best considered as melanotic carcinomata, analogous to the epidermal pigmented growths of the skin.

To complete the analogy it would seem that we should have true naevi, that is, developmental displacements of ectodermal (retinal) melanoblasts into the anterior layer. Such may occur in a sense in the previously mentioned " klumpenzellen "; but there seems to be no record of just such a case, though the present one at least has its suggestive features.

The case under discussion may come under the category of a rather extensive melanosis arising through a proliferation of the mesodermal melanoblasts until they completely fill the whole 
thickness of the iris back to the posterior retinal wall. They consist of fusiform shaped cells with oval or round nuclei containing a very variable number of granules. Amongst them are larger, much more darkly pigmented, branching cells which seem more likely to be phagocytic chromatophores. The cells do not appear to be undergoing mitosis or cell division and the general character is not that of malignancy.

To emphasise the point of view concerning these cells as being constantly or even partly a contributing factor may I repeat what I have already tried to demonstrate through my sections as to the possible genesis of the stroma pigment cells. In the stroma there are two types of pigment-carrying cells concerning whose derivation there is still some confusion and doubt. It is said that they are of mesodermal origin. One of these apparently is a true chromatophore, being "dopa" negative, mesoblastic, and identical morphologically with the chromatophores of the skin. The other is " dopa " positive and it is therefore looked upon by many as a mesoblastic melanoblast. From our sections we would say rather that they are ectodermal melanoblasts as one can see them growing in from the posterior epithelial layer. Our sections would further tend to endorse the view that the physiological behaviour of these cells as noted in an embryonic state or in the process of true tumour formation is a repetition of the cellular behaviour during an embryonic state. It is certain that tumours, both functionally and morphologically are little more in some respects than a recapitulation of a more primitive or embryonic state. Von Hansemann has referred to such cell behaviour as kataplasia. This all tends to support the opinion that melanoblasts in the stroma of the iris are at least sometimes epidermal in origin. Thus the melanoma of the iris can be brought into line with Masson's theory of a nervous derivation of the skin naevi, as the ectoderm of the interior of the eye is derived from the fore-brain (diencephalon).

The problem is not simple; these mesoblastic melanoblasts of the iris stroma have the appearance of mesoblastic cells as our bleached sections show and many on very good grounds would call them mesoblastic. It is true that they are " dopa" positive (i.e., they contain a specific ferment for producing melanin from dihydroxyphenylalanine) which is an ectodermal characteristic. If it is true that they are mesodermal then we have another instance, of which in the eye there are many, of a phylogenetic aberration. These are cells which partake of the characteristic of both ectoderm and mesoderm. One might mention as another instance the development of the smooth muscle of the iris from ectoderm. 


\title{
REFERENCES
}

Fuchs.-Textbook of Ophthalmology (Duane). 1923.

Arch.f. Ophthal., Bd. LXXXVI, S. 155.

Gilbert.-Arch.f. Augenheilk., Vol. LXXXVIII, S. 143, 1921.

Treacher Collins.-Roy. Lond. Ophthal. Hosp. Reps., Vols. I-XII, p. 273.

Collins and Mayou.-Pathology of the Eye, p. 18.

Parsons.-Pathology of the Eye. Vol. I Part I, p. 322,

Morax.-Bull. de la Soc. Franc. d'Ophtal., Vol. XLIV, p. 365, 1931.

Houwer.-Trans. Ophthal. Soc. U.K., Vol. XLVIII, p. 167, 1928.

BOYD.-Pathology of Internal Diseases, p. 485.

MaCCALLUM.- Textbook of Ophthalmology, p. 995, 1928.

MASson -Bull. Assoc. Frang. pour l'Etude du Cancer, p. 303, June 20, 1921 ; Ann.d'Anat. Pathol., Vol. III, pp. 417, 657, 1926.

VERHOEFF.-Arch. of Ophthal., Vol. XL, p. 486, 1911.

SALZMANN.- Anatomy of the Human Eyeball, 1912.

HENKE and LUBARSCH.- - Handbuch der speziellen pathologischen Anatomie und Histologie. Erster teil, 11/1, S. 537, 1928.

\section{COLOBOMATA OF THE OPTIC NERVE SHEATH IN RATS}

\author{
BY \\ John V. V. Nicholls* and Katharine TANSLey \\ (FROM THE DEPARTMENT OF PHYSIOLOGY, \\ UNIVERSITY COLLEGE, LONDON)
}

AN examination of a collection of histological sections of rat eyes, prepared by one of us in connection with various investigations, disclosed some interesting examples of developmental defect about the optic nerve head. These were ectasias of the retina passing between the edge of the lamina cribrosa and the sclera into the optic nerve sheath, and might be considered as colobomata of the nerve sheath. Altogether sections through the optic nerve of 214 eyes were examined and most of these were serial sections. Ten cases presented this condition in greater or less degree, but showed certain differences from those described up to the present.

Quite an extensive literature has grown up around the whole subject of colobomata of the optic nerve. It is not our purpose, however, to deal with this in great detail. From our point of view it is interesting to note that Ginsberg (1896) reported a case in a rabbit showing a deep excavation of the optic nerve. A similar case in man, in which the lamina cribrosa was also defective was described by Goerlitz (1897). Von Hippel (1900) reported another, though more complicated case. Coats (1908) described two cases in an anencephalic monster where a pouch of retina ran through the lamina cribrosa into the substance of the optic nerve. In his paper, he summed up the whole question. While admitting the

\footnotetext{
*Travers Allen Travelling Fellow.
} 